\title{
Anisotropy in plastic deformation of extruded magnesium alloy sheet during tensile straining at high temperature
}

\author{
David E Cipoletti ${ }^{1,3^{*}}$, Allan F Bower ${ }^{1}$ and Paul E Krajewski ${ }^{2}$
}

\author{
* Correspondence: \\ david.cipoletti@bucknell.edu \\ ${ }^{1}$ School of Engineering, Brown \\ University, Providence, RI 02912, USA \\ ${ }^{3}$ Present Address: College of \\ Engineering, Bucknell University, \\ Lewisburg, PA 17837, USA \\ Full list of author information is \\ available at the end of the article
}

\begin{abstract}
Experimental measurements are used to characterize the anisotropy of flow stress in extruded magnesium alloy AZ31 sheet during uniaxial tension tests at temperatures between $350^{\circ} \mathrm{C}$ and $450^{\circ} \mathrm{C}$, and strain rates ranging from $10^{-5}$ to $10^{-2} \mathrm{~s}^{-1}$. The sheet exhibits lower flow stress and higher tensile ductility when loaded with the tensile axis perpendicular to the extrusion direction compared to when it is loaded parallel to the extrusion direction. This anisotropy is found to be grain size, strain rate, and temperature dependent, but is only weakly dependent on texture. A microstructure based model (D. E. Cipoletti, A. F. Bower, P. E. Krajewski, Scr. Mater., 64 (2011) 931-934) is used to explain the origin of the anisotropic behavior. In contrast to room temperature behavior, where anisotropy is principally a consequence of the low resistance to slip on the basal slip system, elevated temperature anisotropy is found to be caused by the grain structure of extruded sheet. The grains are elongated parallel to the extrusion direction, leading to a lower effective grain size perpendicular to the extrusion direction. As a result, grain boundary sliding occurs more readily if the material is loaded perpendicular to the extrusion direction.
\end{abstract}

Keywords: Magnesium alloys; Grain boundary sliding; Creep; Finite element method; Crystal plasticity

\section{Background}

Wrought magnesium alloys commonly display anisotropic behavior during deformation, which has a profound influence on their ductility and forming limits. This anisotropy results both from the production of the sheet or extruded materials, and from deformation induced during forming of the desired shape [1]. Texture has been studied in a wide variety of the hexagonal metals and has been shown to influence plastic deformation for a majority of them, including titanium, zinc, and zirconium [2-9]. The influence of texture on deformation in magnesium has been studied, however, its effect is not completely understood [10,11]. During room temperature deformation of magnesium alloys, plastic deformation occurs mostly by $\langle a\rangle$ slip on the basal plane or by $\{10 \overline{1} 2\}\langle\overline{1} 011\rangle$ twinning. The limited number of systems for plastic deformation, together with the strong deformation induced texture, result in low ductility [12]. For example, the orientation of the tensile axis with respect to the extrusion direction was shown to affect the strength, ductility, and work hardening in tensile specimens of

\section{Springer}

(c) 2013 Cipoletti et al.; licensee Springer. This is an open access article distributed under the terms of the Creative Commons Attribution License (http://creativecommons.org/licenses/by/2.0), which permits unrestricted use, distribution, and reproduction in any medium, provided the original work is properly cited. 
magnesium alloy AZ31 [13,14]. The anisotropy observed during room temperature deformation of extruded sheet persists at elevated temperature [15]. However, the origin of the anisotropy at elevated temperatures is less certain. As temperature is increased, $\langle a\rangle$ slip on the prismatic plane becomes active, as well as $\langle c+a\rangle$ slip on the pyramidal plane [16-18]. At the same time, additional deformation mechanisms such as grain boundary sliding and grain boundary diffusion become active, significantly increasing ductility. However, there is still debate on whether the increase in ductility is due to the activation of additional slip systems or the additional deformation mechanisms [19]. Specifically, the importance of $\langle c+a\rangle$ slip to increase ductility during elevated temperature deformation is discussed in the work of Hutchinson [12]. Barnett et al. show that anisotropy is affected by an increase in temperature through the activation of additional deformation mechanisms specifically grain boundary sliding (GBS). Their work suggests that an increase in the fraction of strain due to GBS is responsible for the decrease in the Lankford r-value that occurs with increasing temperature during tensile straining of magnesium AZ31 sheet [20]. Stanford et al. [21] argues against this conclusion based on their measurements of observable shear at grain boundaries during tensile tests between 25 and $250^{\circ} \mathrm{C}$, and supports the conclusion that increased prismatic and pyramidal slip activity is responsible. Recently, a study was performed on compression of samples made from equal channel angular extrusion (ECAE) at midrange temperatures by Foley et al. [22]. They found that in compression tests between $115^{\circ} \mathrm{C}$ and $200^{\circ} \mathrm{C}$, texture effects dominated the mechanical properties of the material, and furthermore, that strength and ductility could be enhanced by fine tuning the ECAE process to achieve grain refinement and specific texture. These observations suggest that the key to developing processing maps to obtain highly formable magnesium alloys is to understand the relationship between crystallographic texture evolution and the prevalent deformation mechanisms. Thus, based on the conclusions discussed here, research into the interplay between GBS and dislocation creep, specifically slip on the $\langle c+a\rangle$ system is necessary.

With this in mind, the goal of this study is to determine the nature and causes of plastic anisotropy during elevated temperature straining of extruded magnesium alloy AZ31 sheets, using a combination of experiments and numerical simulations. Successful implantation of this combined approach to influence industrial processing application has previously been carried out by Krajewski et al. with Al-Mg alloys [23]. They utilize a multiscale modeling framework such that a microstructure-based finite element model is incorporated into a computational model of dome forming experiments which in turn is incorporated into a macroscale model of a license plate pocket forming operation. This multiscale modeling framework provides a direct link from the influence of deformation mechanisms at the microstructural level to large scale forming operations in an industrial application specifically within the automotive industry [23]. Our investigation focuses on deformation mechanisms that occur at temperatures and strain rates typical of the quick plastic forming process (QPF). Quick plastic forming is a hot blow forming process developed by General Motors for forming sheet material into complex shapes at a strain rate and temperature acceptable for production volumes [24]. The process is adapted from the superplastic forming process (SPF) that allows large tensile elongations without failure by straining at slow rates and elevated temperatures [25]. Elevated temperature processes such as QPF are necessary to produce complex 3D parts from magnesium alloy sheet. 
Uniaxial tensile tests and strain rate jump tests were used to determine the flow stress of extruded magnesium alloy AZ31 sheet as a function of strain rate and temperature. Tests were conducted for specimens with tensile axis both parallel and perpendicular to the extrusion direction. A significant anisotropy was observed at low strain rates, which decreases as the strain rate is increased. There are two possible causes for this anisotropy: firstly the sheet is textured, and loading orientations which favor basal slip tend to have faster rates of dislocation creep and consequently lower flow stresses. Secondly, extruded sheet has a non equi-axed grain structure, with the grains elongated parallel to the extrusion direction. As a result, the grain boundary structure is anisotropic, and tends to promote grain boundary sliding when the loading axis is transverse to the extrusion direction.

To distinguish between these two possible sources of anisotropy, numerical simulations were used to quantify the relative contributions of dislocation creep and grain boundary sliding to plastic flow in the magnesium alloy sheet specimens. In an earlier paper by Cipoletti et al. [26], the microstructure based model developed by Bower and Wininger [27] was extended and calibrated for magnesium alloy AZ31. In this work, the previously developed model is utilized to specifically investigate the root of the anisotropic behavior of extruded sheet material. The computations account for dislocation creep within the grains using a crystal plasticity model appropriate for hcp metals, while using a sharp-interface model to account for grain boundary diffusion and sliding. The model was used to compute the flow stress of extruded AZ31 alloy specimens, with microstructures taken directly from experimental micrographs, as functions of temperature and strain rate. The predicted flow stresses were found to be in excellent agreement with experiment. The computations show that anisotropy in grain shape is the principal cause of flow stress anisotropy in extruded AZ31 sheet, with texture induced plastic anisotropy playing a secondary role.

The remainder of this paper will be organized as follows. First an experimental analysis of the extruded magnesium AZ31 sheet material will be explained along with conclusions and implications of the results. Then the finite element model will be discussed in greater detail along with the each of the deformation mechanisms that are modeled. Finally, the model will be employed to investigate the experimental results and the implications of its findings will be discussed along with the conclusions of the study.

\section{Methods}

\section{Sample preparation and observation}

As received material, annealed samples, and deformed samples were analyzed using optical microscopy to determine grain size and general topography, and were analyzed using the method of electron backscatter diffraction (EBSD) on the scanning electron microscope (SEM) to determine texture and grain orientation. The samples were prepared in careful adherence to the following procedure for observing the microstructure characteristics. Each specimen was first cut using a low speed diamond saw to minimize any chance of twinning during the cutting process. The specimens were then mounted in epoxy cold mounts to avoid the possibility of a change in the microstructure due to the heat and pressure associated with a hot mount. Conductive filler was used at the specified ratio for each mount that housed specimens destined to be analyzed using EBSD to ensure electrical 
conductivity. The samples were mechanically polished with fine grain $\mathrm{SiC}$ paper, followed by finer polishing using suspended alumina solution with particle size $1 \mu \mathrm{m}, 0.3 \mu \mathrm{m}$, and $0.05 \mu \mathrm{m}$ in order of decreasing particle size. Specimens to be observed optically were etched using an acetic-picric acid etchant. Grain size was measured on the optically observes samples using the linear intercept method in accordance with ASTM standard E112-96. Samples to be observed using EBSD were electro-polished in a solution of 10 percent nitric acid in methanol at 2 volts for one second with an aluminum cathode and a copper anode. All EBSD imaging was done on a JEOL 845 scanning electron microscope, and all EBSD patterns were obtained using an Oxford Instruments HKL Nordlys detector and the Oxford Instruments INCA software package.

\section{Material specifications}

Magnesium alloy AZ31 with composition Mg - Al 3.5 - Zn 1.5 - Mn $0.2-\mathrm{Cu} 0.05-$ Ca 0.04 - Fe 0.01 - Ni 0.01 (in weight percent) was extruded into sheet material 175 $\mathrm{mm}$ wide and $\mathrm{xx} \mathrm{mm}$ thick. Elevated temperature tensile test specimens were cut from the extruded sheet so that the tensile axis was rotated $0^{\circ}$ or $90^{\circ}$ from the extruded direction (ED). The specimens cut $0^{\circ}$ to the ED were removed from sheet with a final thickness of $1.30 \mathrm{~mm}$, and the specimens cut $90^{\circ}$ to the ED were removed from sheet with a final thickness of $1.67 \mathrm{~mm}$.

Optical microscopy and EBSD were used to characterize the initial microstructure. Due to the extrusion process, the grain size measured on the transverse face of the specimens loaded $0^{\circ}$ to the ED was approximately $18 \mu \mathrm{m}$ whereas on the specimens loaded $90^{\circ}$ to the ED the initial grain size was measured as approximately $9 \mu \mathrm{m}$ (Figure 1 describes with more clarity the exact face that was observed). This suggests that during the extrusion process, the grains were elongated in the extrusion direction. Thus, although the same grains are being measured, they have an apparent grain size based on the orientation. Figure 2 shows EBSD texture maps for the face oriented $0^{\circ}$ and $90^{\circ}$ to the ED where this effect can be observed. The extrusion process also imparts a strong texture in the sheet,

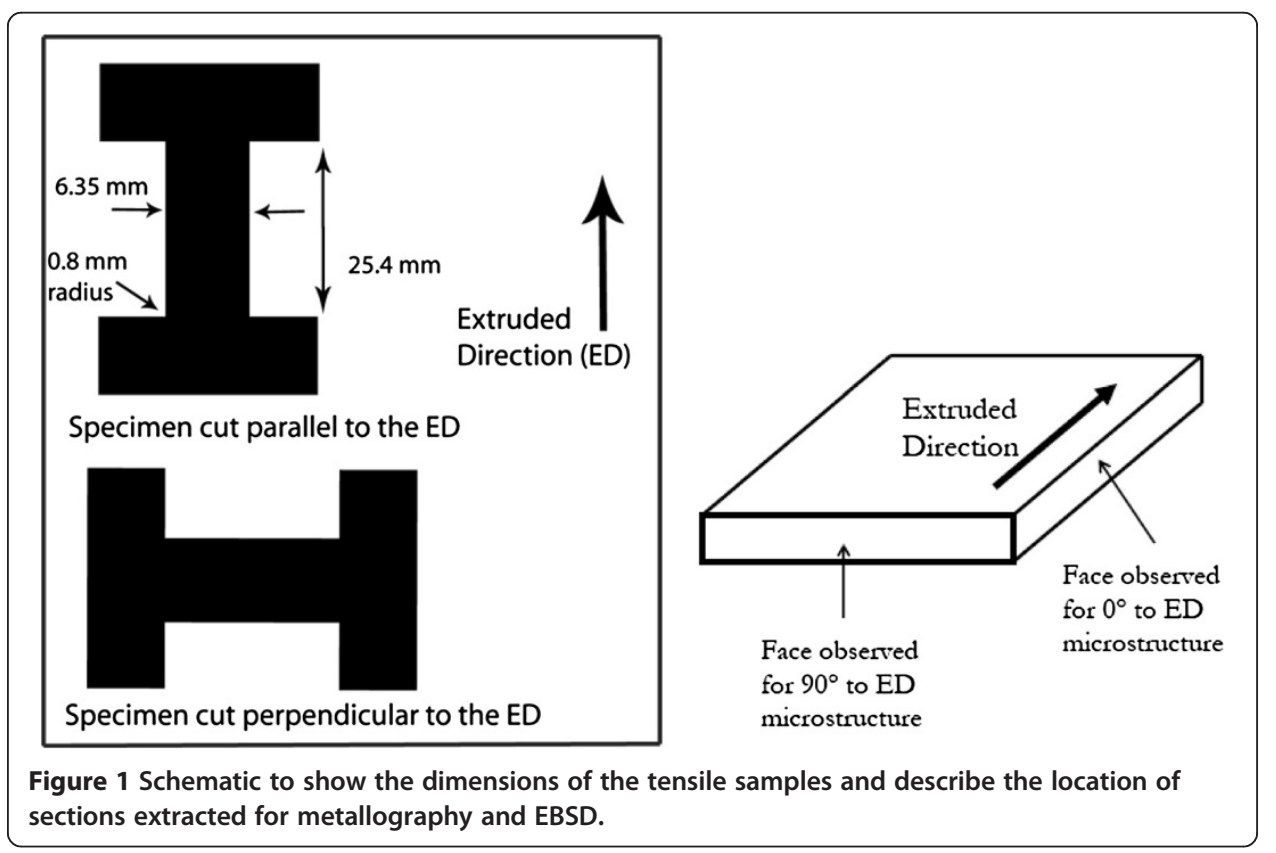




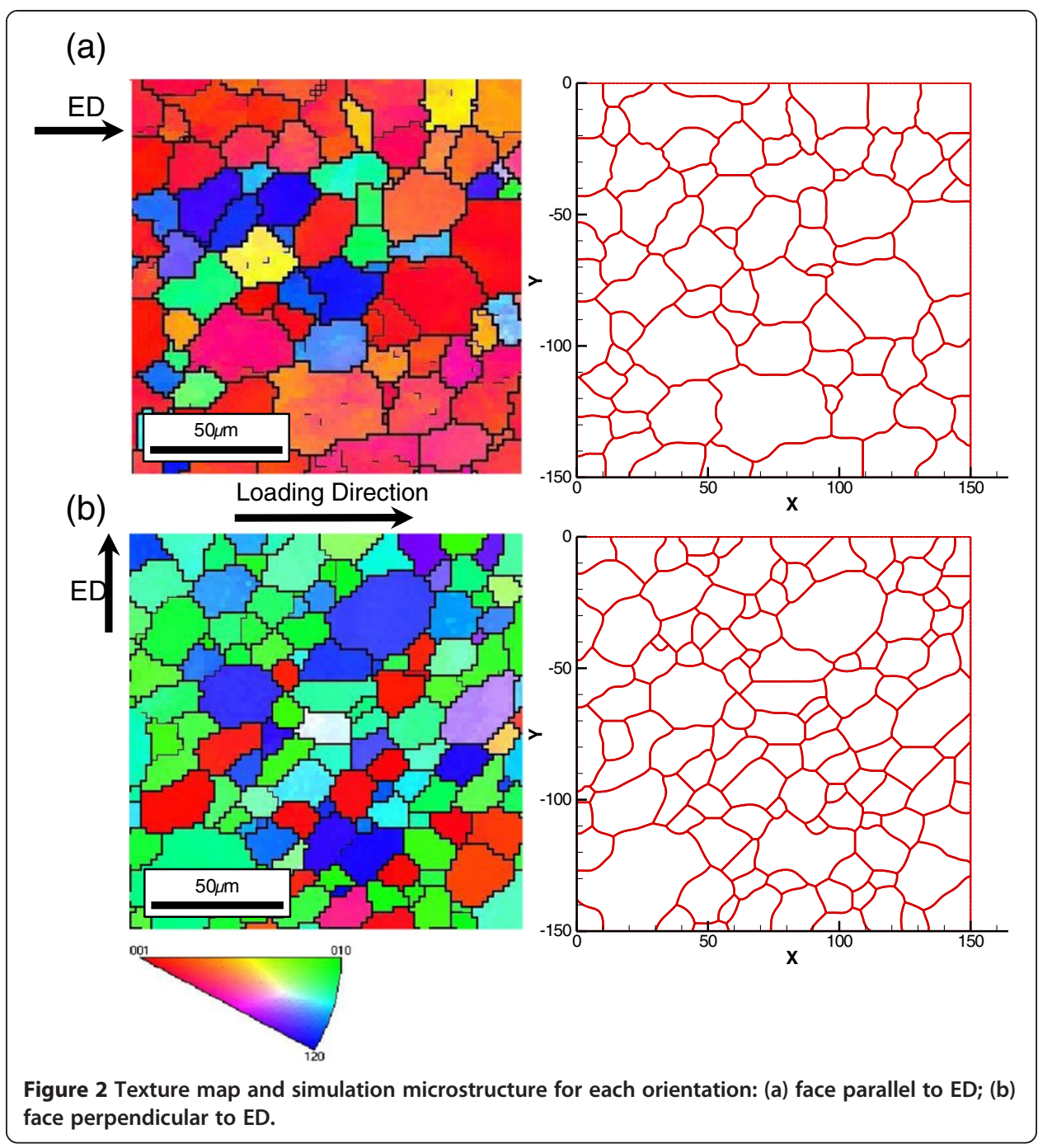

which can also be observed in EBSD texture maps. As observed in Figure 2a, most grains are oriented with the basal plane normal to the surface for the specimen oriented $0^{\circ}$ to the $\mathrm{ED}$, whereas the grains of the specimen oriented $90^{\circ}$ to the ED are mostly oriented in the $\langle 10 \overline{1} 0\rangle$ and $\langle 11 \overline{2} 0\rangle$ directions (Figure $2 \mathrm{~b}$ ). This suggests that in addition to elongating the grains, the extrusion process tends to rotate the grains so that the basal plane is aligned along the extrusion direction. Thus, by adjusting the loading direction to be $0^{\circ}$ to the ED, the tensile axis is aligned with the long axis of the elongated grains and the basal plane of a majority of the grains. In contrast, if the loading direction is $90^{\circ}$ to the ED, the tensile axis is perpendicular to the long axis of the elongated grains and perpendicular to the basal plane of most grains. It is important to note that the texture of the specimens that these microstructures are meant to model does not change but the orientation of the tensile axis rotates against the strong texture of the specimen.

\section{Elevated temperature tensile tests}

Elevated temperature tensile tests were performed to determine the response of the material to an applied strain rate at temperature. A standard dog bone style elevated temperature tensile specimen was used for all tests. The specimen dimensions are 
shown in Figure 1. Each experiment was performed on an Instron 5568. The tensile specimens were loaded into a pre-heated furnace, and testing was begun 2.5 minutes after the specimen reached testing temperature to ensure even temperature distribution in the specimen. At the completion of the test, which was determined by fracture in all cases, the specimen was immediately removed and quenched in water to preserve the microstructure. Two different types of tensile tests were performed on the specimens, a constant strain rate test and a step strain rate test.

Constant strain rate to failure tests were performed at two different strain rates at $450^{\circ} \mathrm{C}$ for tensile specimens loaded parallel and perpendicular to the extrusion direction, the results of which are seen in Figure 3. The crosshead speed of the test was varied to account for uniform thinning of the sample during deformation. This was done using an algorithm through the test frame, but does not guarantee constant strain rate under conditions of extreme necking. A greater flow stress was reached in the material when the specimen was pulled at a faster strain rate and the material exhibited more ductility at the lower strain rate.

Step strain rate tests were performed to obtain the steady state flow stress as a function of strain, strain rate, and temperature. In these tests, the specimen was first subjected to an initial strain rate of $3.0 \times 10^{-3} s^{-1}$ to ensure that the specimen was firmly positioned in the testing apparatus and to stabilize the microstructure. Then the specimen was subjected to multiple strain rates sequentially in decreasing order from $3.0 \times 10^{-2} s^{-1}$ to $1.0 \times 10^{-4} \mathrm{~s}^{-1}$. Each strain rate was held constant for a minimum of 2 percent engineering strain. When the stress had ceased to decay after each change in strain rate, reaching essentially a steady state value, the stress was recorded in the specimen. Each specimen was subjected to multiple strain rate cycles so that the flow stress at multiple strains could be determined based on a linear interpolation of the coordinates for the steady state stress and strain at each strain rate. An example stress vs. strain curve that shows two complete cycles of a step strain rate test is shown in Figure 4. The approximately horizontal lines show how the

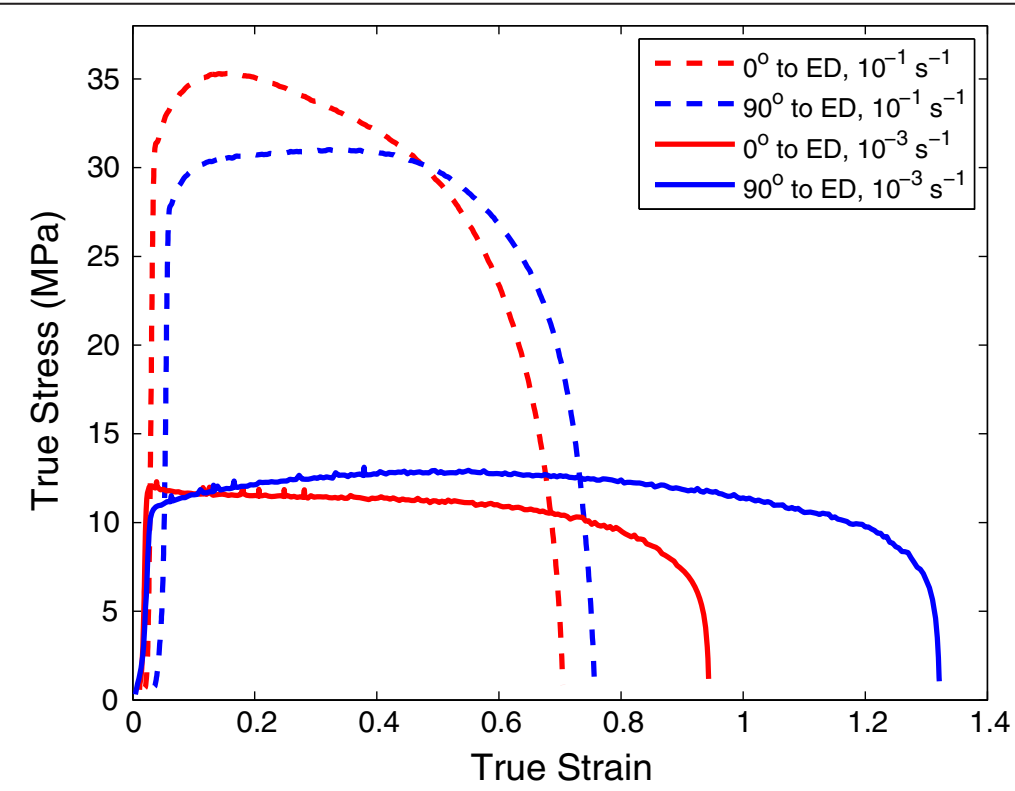

Figure 3 Stress vs. strain curves for magnesium AZ31 specimens oriented with the tensile axis $0^{\circ}$ and $90^{\circ}$ to the extruded direction tested at $450^{\circ} \mathrm{C}$ at a constant strain rate to failure of $10^{-1} \mathrm{~s}^{-1}$ and $10^{-3} \mathrm{~s}^{-1}$. 


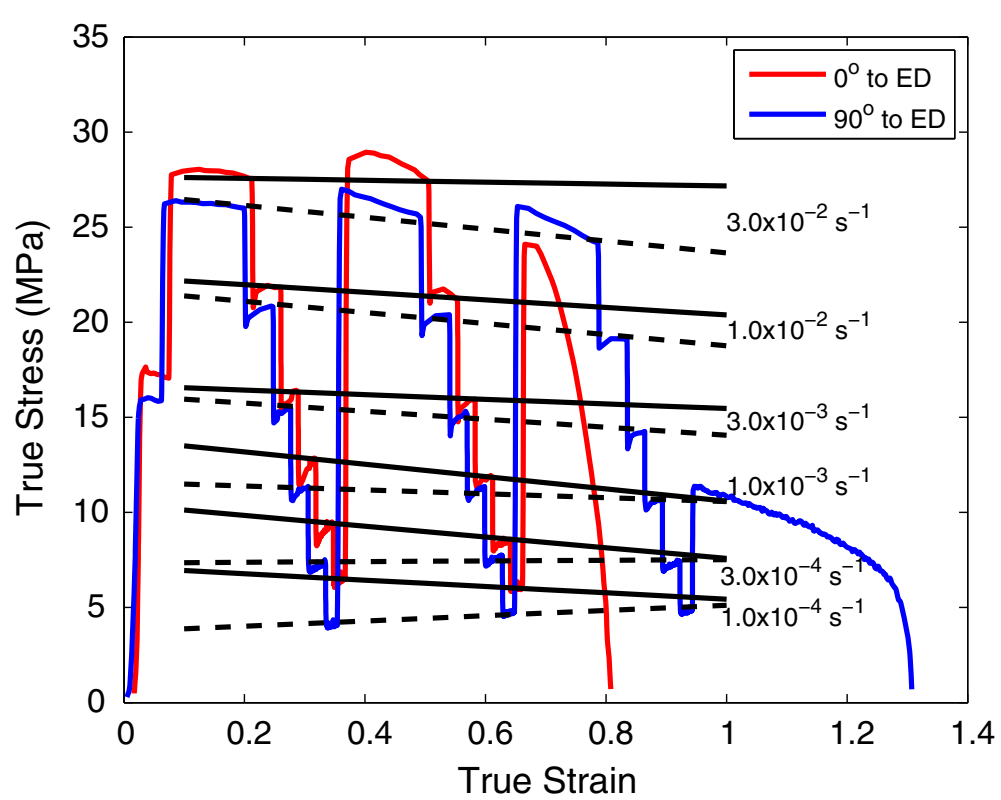

Figure 4 The true stress vs. true strain curve for multiple strain rate cycles during the step strain rate test for specimens oriented $0^{\circ}$ and $90^{\circ}$ to the ED performed at $450^{\circ} \mathrm{C}$. The flow stress at a given strain for a specific strain rate is interpolated from the linear fits to the steady state stress at each strain rate shown on the plot for each orientation (solid lines for the $0^{\circ}$ to the ED data, dashed lines for the $90^{\circ}$ to the ED data).

stress was interpolated to give the steady state flow stress at various strain rates. It is assumed that the microstructure remains relatively constant during testing at each strain rate and that minimal hardening or softening occurs in the sample during the test. This assumption is supported by observing that the stress at each strain rate recorded at low and high levels of strain was approximately equal; the interpolation lines in Figure 4 have close to no slope. However, there is a change in the stress during each strain rate step, thus the range of error possible from the tests was recorded and error bars were placed on the plots compiled from the step strain rate test results.

\section{Model description}

Recently, Cipoletti et al. [26] developed a microstructure based finite element model that predicts elevated temperature deformation mechanisms in magnesium alloys. Details of the model as well as how it was calibrated and validated are discussed in ref. [25]. In the present study, the model is utilized to understand the relationship between anisotropy and the active deformation mechanisms in magnesium AZ31 extruded sheet. Thus, a brief description of it is included here for clarity and to highlight how it was adapted to study the effect of anisotropy in this work.

Two representative two-dimensional microstructures have been assembled directly from micrographs of the specimens cut $0^{\circ}$ and $90^{\circ}$ to the ED (Figure 2), one of which is shown in Figure 5. The orientation of each grain in the simulation microstructure has been taken directly from the actual material using data obtained from the EBSD analysis. Each microstructure is modeled as a collection of single crystal grains separated by sharp grain boundaries. A constant strain rate is applied in the $\mathrm{x}$ direction to induce a state of plane strain uniaxial extension in the polycrystal. Three mechanisms of deformation are accounted for 


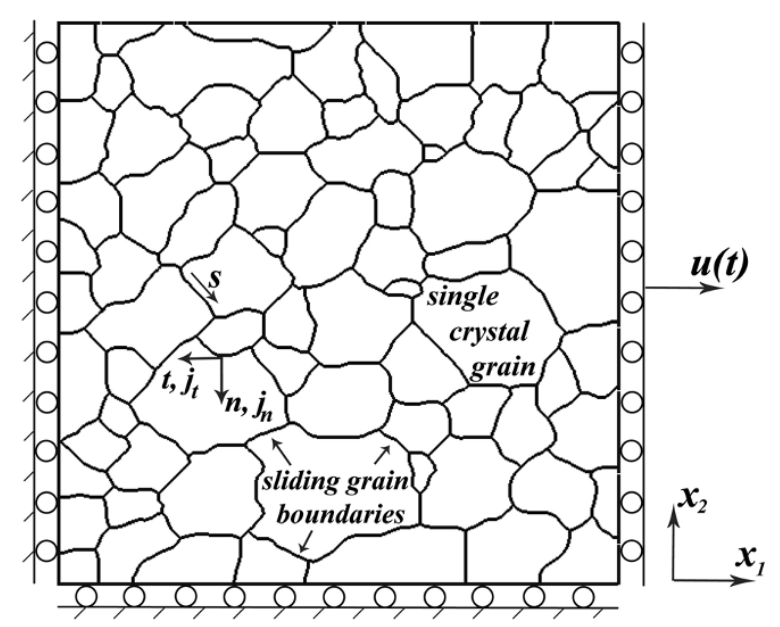

Figure 5 Schematic of the microstructure used FEM simulations; $s$ denotes arc length measured from some convenient point on a representative grain boundary; $t$ and $n$ denote unit vectors tangent and normal to the boundary.

in the polycrystal: (i) dislocation creep (DC) within the grains; (ii) grain boundary diffusion (GBD); and (iii) grain boundary sliding (GBS). The assumptions and constitutive equations that are used to model these processes will be described in more detail below.

The main objective of the finite element simulations is to calculate the stress and displacement distributions induced in the microstructure. The results are used to deduce the volume average uniaxial stress $\sigma$ as a function of the applied uniaxial strain and strain rate (calculated from the displacements applied to the boundary of the microstructure). After a brief elastic transient, the uniaxial stress settles to a constant value, which depends on the applied strain rate. Consequently, our focus is placed on the variation of steady-state flow stress, $\sigma$ as a function of uniaxial strain rate, $\dot{\varepsilon}$.

\section{Dislocation creep}

A classical single crystal model is used to describe dislocation creep within the grains, all of which are modeled as hexagonal close packed crystals. The strain rate $\dot{\varepsilon}_{i j}=$ $\left(\partial \dot{u}_{i} / \partial x_{j}+\partial \dot{u}_{j} / \partial x_{i}\right) / 2$ in each grain is broken down into an elastic and plastic strain rate as.

$$
\dot{\varepsilon}_{i j}=\dot{\varepsilon}_{i j}^{e}+\dot{\varepsilon}_{i j}^{p}
$$

Linear elastic constitutive equations for a transversely isotropic material with Young's modulus $E_{p}$ and $E_{t}$, shear modulus $\mu_{p}$ and $\mu_{t}$, and Poisson's ratio $v_{p}, v_{t p}$, and $v_{p}$ [28] are used to relate the elastic strain rate to the stress rate. Plastically, each grain deforms by shearing on the basal (0001) [11-20], pyramidal (1-100) [11-20], and prismatic (1-101) [11-20] slip systems. The shear rate on a slip system $\dot{\gamma}^{\alpha}$ is determined from the model for solute drag creep proposed by Frost and Ashby [29] as

$$
\dot{\gamma}^{\alpha}=\dot{\gamma}\left(\frac{q^{\alpha}}{\tau_{0}^{\alpha}}\right)^{n}
$$

where $n \approx 5.5$ is the stress exponent, $q^{\alpha}=s_{i}^{\alpha} \sigma_{i j} m_{j}^{\alpha}$ denotes the resolved shear stress on the slip system $\alpha, \tau_{0}$ is the critical resolved shear stress for the slip system $\alpha$, and $\dot{\gamma}$ is 
the characteristic slip rate. The characteristic slip rate is temperature dependent as defined by the following Arrhenius relationship

$$
\dot{\gamma}=\dot{\gamma}_{o} \exp \left(-Q_{D C} / k T\right)
$$

where $\dot{\gamma}_{o}$ is a pre-exponential factor, $Q_{D C}$ is the activation energy for dislocations to escape pinning points, $k$ is the Boltzmann constant, and $T$ is temperature. The strength of the different slip systems in magnesium was taken into account by adjusting $\tau_{0}$. This data was taken from experimental work on single crystal magnesium [16,18,30-32]. The resolved shear stress on the HCP slip systems are of the following ratio, Basal: Prismatic: Pyramidal $=4: 10: 11$ (a more in depth discussion of this choice of ratio is included in ref. [26]). Finally, to determine the plastic strain rate, the shear rate calculated on each of the active slip systems is summed over all slip systems,

$$
\dot{\varepsilon}_{i j}^{p}=\sum_{\alpha=1}^{N} \dot{\gamma}^{\alpha}\left(q^{\alpha}\right)\left(s_{i}^{\alpha} m_{j}^{\alpha}+s_{j}^{\alpha} m_{i}^{\alpha}\right) / 2
$$

where $s_{i}^{\alpha}$ and $m_{i}^{\alpha}$ denote the components of unit vectors parallel to the slip direction and slip plane normal, respectively.

\section{Grain boundary sliding and diffusion}

In addition to DC, the model allows for displacement with respect to adjacent grains along their common grain boundary in response to normal stress, defined as $\sigma_{n}=\sigma_{i j} n_{i} n_{j}$, and shear stress, defined as $\sigma_{t}=\sigma_{i j} t_{i} n_{j}$, acting on a representative boundary. Due to this displacement, discontinuities develop in the velocity field across each grain boundary, which are defined in terms of their normal and tangential component as follows

$$
\begin{aligned}
& {\left[v_{n}\right]=\left(\dot{u}_{i}^{+}-\dot{u}_{i}^{-}\right) n_{i}} \\
& {\left[v_{n}\right]=\left(\dot{u}_{i}^{+}-\dot{u}_{i}^{-}\right) t_{i}}
\end{aligned}
$$

where $u_{i}^{ \pm}$denotes the displacement of each grain immediately adjacent to a point on the grain boundary.

GBS is a result of tangential displacement between adjacent grains along their common grain boundary due to shear stress acting on their interface. The GBS velocity is calculated relative to the adjacent grains using the following linear-viscous constitutive equation

$$
\left[v_{t}\right]=\eta \sigma_{t}
$$

where $\eta$ is the fluidity of the grain boundary. The fluidity of the grain boundary is defined by the following relationship,

$$
\eta=\frac{\Omega \eta_{o} \exp \left(-Q_{G B} / k T\right)}{k T}
$$

where $\Omega$ is the atomic volume and $Q_{G B}$ is the corresponding activation energy for GBD given by Frost and Ashby [29]. Although there has been substantial work defining the relationship between GBS and grain boundary migration in magnesium alloys [33], specifically in relation to their misorientation, grain boundary migration has been neglected in our computations, for simplicity. Note that our computations naturally enforce compatibility between grain boundary sliding, grain boundary diffusion, and dislocation plasticity within the grains. 
GBD is a result of displacement between adjacent grains perpendicular to their common grain boundary due to normal stress acting on their interface. Thinking in terms of energy, the total free energy of the system is increased due to the normal stress acting on the grain boundary. By allowing atoms to diffuse from parts of the grain boundary in compression to the parts of the boundary in tension, the free energy is reduced. This atomic migration has the effect of displacing material points within neighboring grains towards each other in areas of compression and away from each other in areas of tension. This displacement results in a velocity discontinuity across the common grain boundary, defined by the following linear diffusion law

$$
\left[v_{n}\right]=\frac{\Omega D_{G B} \delta_{G B} \exp \left(-Q_{G B} / k T\right)}{k T} \frac{\partial^{2}}{\partial s^{2}}\left[-\sigma_{n}\right]
$$

where $D_{G B} \exp \left(-Q_{G B} / k T\right)$ is the grain-boundary diffusivity and $\delta_{G B}$ is the thickness of the interface where the diffusion is occurring.

All the grain boundaries in our microstructure terminate either at a triple junction, or at the edge of the specimen. The constraints which control behavior at these points are explained in detail in ref. [27].

\section{Finite element simulations}

The finite element method is used to solve the equations of mechanical equilibrium, the constitutive equations $(1,2,3,4)$ for the grains, and the stress-velocity discontinuity equations $(5,6,7,8)$. Deformation within the grains is modeled using a standard procedure. Line elements are introduced along the grain boundaries to interpolate the velocity discontinuity as well as the distribution of the normal and tangential stress along the boundary to solve the equations governing GBS and GBD. Details of these procedures are provided in ref. [27].

The stress and displacement fields in the microstructure are provided as output from the finite element computations, from which the contribution to the total strain rate from each deformation mechanism is determined as follows,

$$
\begin{aligned}
& \dot{\varepsilon}_{i j}^{\text {dislocation }}=\frac{1}{V} \int_{V} \sum_{\alpha} \dot{\gamma}^{\alpha} \frac{1}{2}\left(s_{i}^{\alpha} m_{j}^{\alpha}+s_{j}^{\alpha} m_{i}^{\alpha}\right) d V \\
& \dot{\varepsilon}_{i j}^{\text {sliding }}=\frac{1}{V} \int_{\Gamma}\left[v_{t}\right] \frac{1}{2}\left(n_{i} t_{j}+t_{i} n_{j}\right) d s \\
& \dot{\varepsilon}_{i j}^{\text {diffusion }}=\frac{1}{V} \int_{\Gamma}\left[v_{n}\right] n_{i} n_{j} d s
\end{aligned}
$$

where $V$ denotes the area of the entire 2D microstructure and $\Gamma$ denotes the assembly of grain boundaries within $V$. The rate of shear on each slip system is used to compute the plastic strain rate resulting from dislocation creep, while the velocity discontinuity due to the shear and normal stress acting on the grain boundary is used to compute the plastic strain rate resulting from grain boundary sliding and diffusion, respectively.

\section{Setup of initial conditions}

The model was validated for deformation of magnesium alloy AZ31 at $450^{\circ} \mathrm{C}$ in [26]. The material model parameters from this process are shown in Table 1. The model can be shown to account for changes in temperature as long as testing remains at temperature 
Table 1 Values for material parameters used in the FEM simulations

\begin{tabular}{ll}
\hline Parameter & Value \\
\hline Grain size $L$ & $16 \mu \mathrm{m}$ \\
Melting Temperature $T_{M}$ & $923 \mathrm{~K}$ \\
Atomic volume $\Omega$ & $2.32 \times 10^{-29} \mathrm{~m}^{3}$ \\
Elastic constant, $C_{11}$ & $59.7 \mathrm{GN} \mathrm{m}^{-2}$ \\
Elastic constant, $C_{33}$ & $61.7 \mathrm{GN} \mathrm{m}^{-2}$ \\
Elastic constant, $C_{44}$ & $16.4 \mathrm{GN} \mathrm{m}^{-2}$ \\
Elastic constant, $c_{12}$ & $26.2 \mathrm{GN} \mathrm{m}^{-2}$ \\
Elastic constant, $C_{13}$ & $21.7 \mathrm{GN} \mathrm{m}^{-2}$ \\
Initial yield stress, basal slip system $\tau_{0}$ & $4 \mathrm{MN} \mathrm{m}^{-2}$ \\
Initial yield stress, prismatic slip system $\tau_{0}$ & $10 \mathrm{MN} \mathrm{m}^{-2}$ \\
Initial yield stress, pyramidal slip system $\tau_{0}$ & $11 \mathrm{MN} \mathrm{m}^{-2}$ \\
Characteristic strain rate pre-exponential $\dot{Y}_{0}$ & $1.76 \times 10^{-8} \mathrm{~s}^{-1}$ \\
Solute drag creep stress exponent $n$ & 5.5 \\
Activation energy for dislocation creep $Q_{D C}$ & $2.39 \times 10^{-19} \mathrm{~J}$ \\
Grain boundary diffusion pre-exponential $\delta_{G B} D_{G B t}$ & $4.74 \times 10^{-8} \mathrm{~m}^{3} \mathrm{~s}^{-1}$ \\
Grain boundary sliding pre-exponential $\eta_{0}$ & $712.6 \mathrm{~m} \mathrm{~s}^{-1}$ \\
Grain boundary diffusion activation energy $Q_{G B}$ & $1.53 \times 10^{-19} \mathrm{~J}$ \\
\hline
\end{tabular}

values where the assumptions made for elevated temperature deformation are still valid. The temperature cannot be reduced to a point where twinning becomes integral to deformation or to where the critical resolved shear stress on the prismatic and pyramidal slip systems has increased substantially over that of the basal slip system.

A change in temperature has a substantial effect on deformation. When the testing temperature was decreased from $450^{\circ} \mathrm{C}$ to $350^{\circ} \mathrm{C}$, the flow stress increased over the range of strain rates tested. The stress exponent was equal to approximately 5 at fast strain rates for both testing temperatures and decreased to between 2 and 4 at decreased strain rates; for the $450^{\circ} \mathrm{C}$ tests the stress exponent decreased more substantially for both orientations. This suggests that grain boundary sliding and diffusion are more prevalent at higher temperatures.

The model accounts for the change in deformation due to a change in forming temperature in the constitutive equations for DC, GBS, and GBD. This change is based on the activation energy for diffusion, which was taken from Frost and Ashby's Deformation Maps [29]. The activation energy for GBS was assumed to be equal to that for diffusion. The pre-exponential terms in the constitutive laws for GBD and GBS were determined previously by Cipoletti et al. [26]. The temperature dependence of DC is similarly accounted for using an Arrhenius relationship for the characteristic slip rate. The activation energy for DC is adjusted slightly from the activation energy for power law creep defined by Frost and Ashby. The pre-exponential term is fit to experiment at $350^{\circ} \mathrm{C}$ and $450^{\circ} \mathrm{C}$.

The starting microstructure used by the finite element simulations was taken directly from an actual micrograph of magnesium AZ31. In this way, the topography of the actual material could be captured as input to the model including the grain shape, the relative size of the grains, the path of the grain boundaries, and the orientation of the grains. This was done by taking the micrograph obtained using the EBSD method on the SEM (Figure 2) and mapping the grain and grain boundary information into a 
format that could be understood by the finite element code (Figure 5). The grains show good agreement with the actual data and although the grain orientation is not shown on the simulation micrograph it has been mapped directly from the EBSD data.

\section{Results and discussion}

Both experiments and computations were used to determine the variation of flow stress with applied strain rate. Representative results are shown in Figure 6. The relationship between stress and strain rate can be described by a relationship of the form

$$
\dot{\varepsilon}=A \sigma^{n}
$$

where $A$ is a constant and $n$ is the stress exponent. Thus, the stress exponent could be extrapolated from the results. The strain rate sensitivity $m$, which is defined as

$$
m=\frac{d(\log (\sigma))}{d(\log (\dot{\varepsilon}))}
$$

and is equal to the inverse of the stress exponent, $n$, can also be interpreted from the results. A change in the stress exponent (and in the strain rate sensitivity) is often used to gain insight on the prominent deformation mechanisms in the microstructure.

The results of experimental step strain rate tests are plotted in Figure 6, for two orientations of the tensile axis with respect to the extrusion direction, and for two temperatures. For all cases, as the strain rate is increased to faster rates the flow stress increases. The stress exponent can be extracted from the curves using equation (10). At $450^{\circ} \mathrm{C}$ the stress exponent is equal to approximately 5 for high strain rates. When the strain rate is decreased, the stress exponent for the specimen loaded $90^{\circ}$ to the ED decreases below 2, whereas for the specimen loaded $0^{\circ}$ to the ED, it decreases to

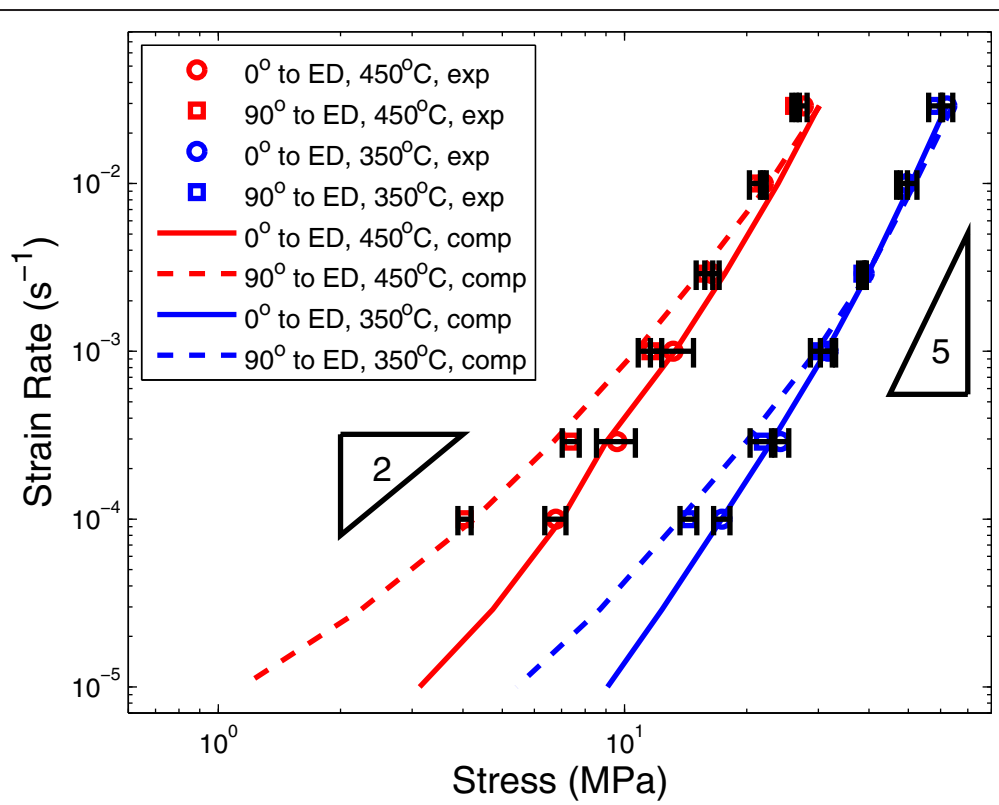

Figure 6 Comparison of measured and predicted flow stress as a function of strain rate for experimental and computational results. 
approximately 3. For a decrease in testing temperature to $350^{\circ} \mathrm{C}$ there is an increase in flow stress across the range of strain rates tested. The stress exponent remains at approximately 5 at fast strain rates, but there is a smaller transition to the lower strain rates, to approximately 4 for the specimen oriented with the tensile axis $0^{\circ}$ to the ED and approximately 3 for the specimen oriented with the tensile axis $90^{\circ}$ to the ED.

The finite element predictions show good agreement with the experimental curves of flow stress vs. strain rate for when the tensile axis is oriented $0^{\circ}$ and $90^{\circ}$ to the extrusion direction at a testing temperature of $450^{\circ} \mathrm{C}$ and $350^{\circ} \mathrm{C}$, as shown in Figure 6. In the high strain rate regime the stress exponent, $n$, approaches 5 for each curve (a strain rate sensitivity of 0.2 ). The model is able to capture the transition in the stress exponent from the high strain rate regime to the low strain rate. The stress exponent decreases to between 2 and 4 in the low strain rate regime. The stress exponent for the specimen loaded perpendicular to the ED is smaller at low strain rates, which suggests that anisotropy affects the stress exponent.

The variation of the stress exponent suggests a change in the deformation mechanism from fast to slow strain rates. A stress exponent of approximately 2 is characteristic of deformation dominated by GBS, whereas for a higher stress exponent, on the order of 5 , it is likely that $\mathrm{DC}$ is dominant. Within the lower range of strain rates at each temperature, there is a greater discrepancy between the two orientations. The change in stress exponent is greater for the data from the sample oriented $90^{\circ}$ to the ED, and furthermore the flow stress extends to smaller values, suggesting that GBS is more prevalent for this orientation.

Our FEA computations are able to partition the total strain rate in the polycrystal into contributions from each deformation mechanism as shown in Figure 7. In general, at slower strain rates the greatest contribution to the total strain rate is GBS, while at

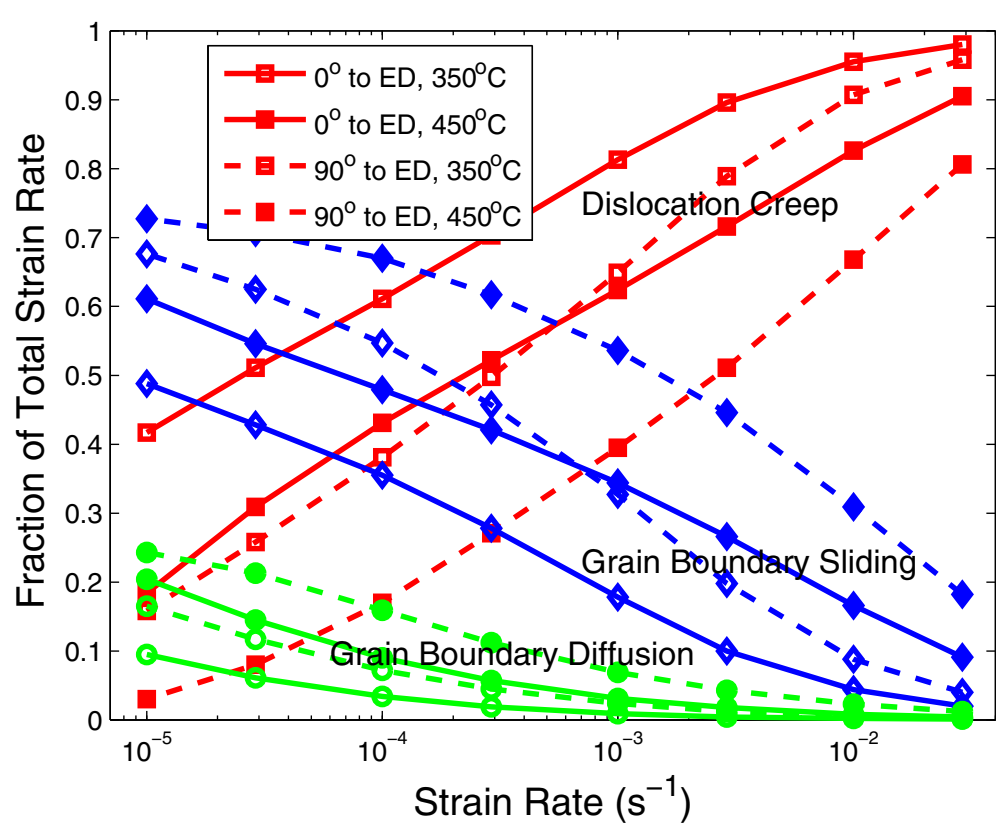

Figure 7 The predicted percent contribution to total strain rate from each deformation mechanism, $\mathrm{DC}, \mathrm{GBD}$, and GBS as a function of strain rate and orientation of the tensile axis at $450^{\circ} \mathrm{C}$ and $350^{\circ} \mathrm{C}$. 
faster strain rates DC emerges as the dominant deformation mechanism. The model confirms that the change in stress exponent observed experimentally is associated with a transition of the dominant deformation mechanism from DC to GBS. In addition, the model elucidates the origin of the anisotropy in flow stress in extruded AZ31 sheet. In the simulation in which the tensile axis is oriented $90^{\circ}$ to the ED, the contribution to the strain rate from GBS as a percentage of total strain rate than the data for the specimen oriented $0^{\circ}$ to the ED at all strain rates, and correspondingly a smaller amount of DC across the range of strain rates tested as shown for the results at $450^{\circ} \mathrm{C}$ and $350^{\circ} \mathrm{C}$ in Figure 7. Thus, changing the loading direction from parallel to perpendicular to the ED drives the transition point of the dominant deformation mechanism from GBS to dislocation creep to occur at higher strain rates. A corresponding transition in strain rate sensitivity is observed when the direction of the loading axis is oriented perpendicular to the extrusion direction.

Figure 7 also shows the effects of temperature on the deformation mechanism. Although the resistance for each deformation mechanism was increased in the model for a decrease in temperature from $450^{\circ} \mathrm{C}$ to $350^{\circ} \mathrm{C}$, DC is shown to be dominant across the range of strain rates for the lower temperature tests at each orientation. The decrease in temperature led to an increase in the amount of plasticity due to DC and a decrease in the amount of GBS and GBD relative to the total strain rate in the microstructure. The transition point between deformation dominated by DC and deformation due to GBS migrated to slower strain rates. In summary for a decrease in temperature from $450^{\circ} \mathrm{C}$ to $350^{\circ} \mathrm{C}$, the strain rate of the transition point decreased one order of magnitude. For the specimen oriented $0^{\circ}$ to the ED, the transition point decreased from $1.5 \times 10^{-4} \mathrm{~s}^{-1}$ at $450^{\circ} \mathrm{C}$ to $1.5 \times 10^{-5} \mathrm{~s}^{-1}$ at $350^{\circ} \mathrm{C}$, and for the specimen oriented $90^{\circ}$ to the ED the transition point migrated from $2.0 \times 10^{-3} \mathrm{~s}^{-1}$ at $450^{\circ} \mathrm{C}$ to $2.3 \times 10^{-4} \mathrm{~s}^{-1}$ at $350^{\circ} \mathrm{C}$.

It is instructive to plot the model's prediction of the contribution from each slip system to the total DC in the simulation, which is investigated in Figure 8 as a function of strain rate at $350^{\circ} \mathrm{C}$ and $450^{\circ} \mathrm{C}$. First, consider the effect of temperature on distribution of strain rate due to DC. Although the flow stress increased substantially in the microstructure during the simulation at $350^{\circ} \mathrm{C}$ there was little change in the distribution of slip from the test at $450^{\circ} \mathrm{C}$. These results are not unexpected due to the fact that the model assumes that the ratio between the slip system strength does not change in this range of temperature, and for each orientation there was no change in the starting microstructure for the simulations at $350^{\circ} \mathrm{C}$ and $450^{\circ} \mathrm{C}$.

However, there is an effect on the orientation on the contribution from each slip system to the total DC in the simulation. It should be noted that the strain rate on each system is normalized by total plastic strain rate due to plastic shearing within the grains, which is significantly smaller than the total strain rate at low strain rates. When the loading is parallel to the ED, slip on the prismatic system is dominant followed by the basal and pyramidal system respectively for the entire range of strain rates. However, when loading is $90^{\circ}$ to the ED, slip on the basal system is dominant followed by slip on the prismatic and pyramidal, which each contribute approximately equal amounts to the total slip. At low strain rates for the sample oriented $90^{\circ}$ to the ED there is a transition of basal dominated slip with slip on the prismatic and pyramidal planes. However, at these low strain rates the strain rate associated with dislocation creep in the microstructure is small, and the flow stress is substantially decreased. 


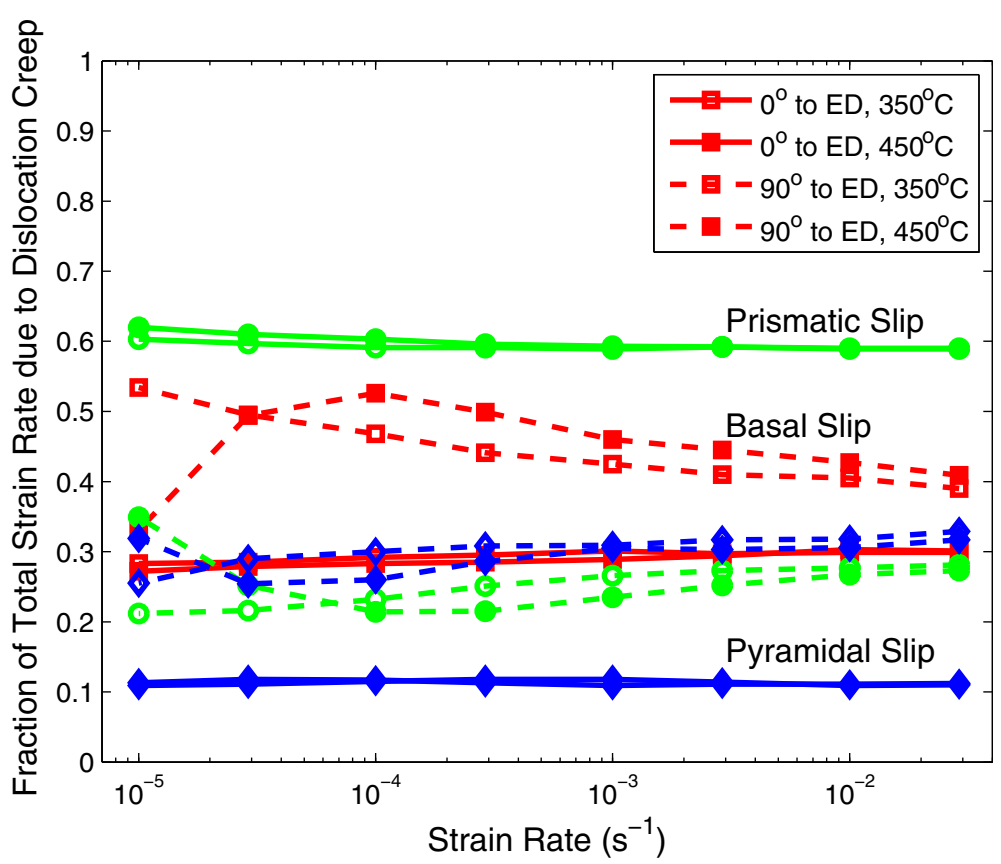

Figure 8 The predicted percent contribution to the total strain rate due to DC from slip on the basal, prismatic and pyramidal slip system in magnesium as a function of strain rate, orientation of the tensile axis and temperature.

These results are worth discussing in comparison to the results of the work introduced previously by Gehrmann et al. [1]. Their group focused on the effect of texture during compression tests from $100^{\circ} \mathrm{C}$ to $200^{\circ} \mathrm{C}$ and thus the boundary conditions are different than those considered here, although the effect of their implementation is similar. They determined that when basal slip was suppressed due to orientation of the basal planes parallel to the compression direction, large fracture strains were made possible by significant slip on the prismatic system that was activated as low as $100^{\circ} \mathrm{C}[1]$. In the work presented here for the sample oriented so that the tensile axis is parallel to the ED, as seen in Figure 2, the basal planes are also parallel to the tensile axis. Due to their orientation, slip on the basal planes is suppressed for a majority of the grains, and thus as seen in Figure 8, DC is accommodated by slip on the prismatic system.

Our results are also worth comparing to the work of Agnew \& Duygulu [19] who by using a combination of experimental and computational techniques performed a comprehensive study of deformation in magnesium AZ31 from room temperature to $250^{\circ} \mathrm{C}$ and strain rates of $10^{-5} \mathrm{~s}^{-1}$ to $0.1 \mathrm{~s}^{-1}$. They concentrated on the effect of strain hardening, strain rate sensitivity, anisotropy, and the stress and strain at fracture. In conclusion they found that the most important factor to increase formability, at temperatures on the high end of the range they investigated, was an increase in the strain rate sensitivity. This conclusion supports the results of the present work where it was shown that the material oriented such that the tensile axis was $90^{\circ}$ to the ED exhibited greater strain rate sensitivity (a lower stress exponent, Figure 6) and also exhibited greater strain prior to failure, Figure 3.

However, Agnew and Duygulu reason that an increase in the activity of the $\langle c+a\rangle$ slip system, which is activated at elevated temperatures, is what leads to the increase in strain 
rate sensitivity [19]. In contrast, the work of Hutchinson et al. comes to a different conclusion than that of Agnew and Duygulu. Their work used a similar material and experimental procedure to Agnew and Duygulu with additional analysis using optical and transmission electron microscopy to specifically look at the contribution of $\langle c+a\rangle$ dislocations [12]. They observed multiple grains after deformation at elevated temperatures and found that two-thirds of those observed did not contain $\langle c+a\rangle$ dislocations. Thus, they concluded that although slip on the pyramidal system is important to increasing the strain rate sensitivity, and thus increasing ductility, it cannot be the only factor. Their results suggested that increased ductility is more dependent on an increase in GBS in the material, which is in turn dependent on the grain size of the material [12]. This conclusion is supported by the work presented here, which shows that GBS is significant to increasing the strain rate sensitivity (decreasing the stress exponent) and that GBS is strongly influenced by the grain size of the material. The contribution from GBS increases for smaller grain size. Furthermore, pyramidal slip is shown to be influential but not dominant. The contribution of slip on the pyramidal plane is significant and is shown to be greater for the specimen loaded $90^{\circ}$ to the ED, which is the specimen that also shows greater strain rate sensitivity at low strain rates. It should be noted that the results presented in this work are at higher temperatures, and as expected, there is a greater contribution of GBS observed. Thus, our conclusions are consistent with results $[19,21]$ that suggest GBS is not responsible for the increase in strain rate sensitivity at temperatures below $250^{\circ} \mathrm{C}$.

Experiments and the finite element model both show anisotropy of the magnesium AZ31 extruded sheet during elevated temperature deformation. The stress exponent and flow stress curves along with ductility and yield strength are shown to be dependent on temperature and strain rate. When the tensile axis is parallel to the extrusion direction, the specimen exhibits greater yield strength and decreased ductility compared to when the tensile axis is rotated $90^{\circ}$. It is assumed that the origin of this behavior lies in the extrusion process, which elongates the grains and aligns the basal plane parallel to the extrusion direction. The apparent grain size of the microstructure for the specimen with the tensile axis aligned $0^{\circ}$ to the ED is $18 \mu \mathrm{m}$ and the grains on this face are strongly oriented in the basal direction, whereas for the specimen with the tensile axis aligned $90^{\circ}$ to the ED the apparent grain size is $9 \mu \mathrm{m}$ and the grains are oriented in the directions perpendicular the basal direction along this face. The orientation of the textured sheet along with the discrepancy in the apparent grain size due to the elongation of grains by extrusion is assumed to lead to the anisotropy shown during deformation.

There are two possible explanations for the anisotropy observed in both experimental tensile tests and in predictions by the finite element model. The first explanation is that the anisotropy results from the texture of the grains, which will effect deformation because of the orientation of the various slip planes with respect to the tensile axis. The second possibility is that the anisotropic behavior results from differences in the GBS mechanism caused by the elongation of the grains parallel to the ED. GBS has been shown to be more prevalent for smaller grain sized material, thus when the tensile axis is parallel to the ED, the apparent grain size is smaller and a greater contribution from GBS would be expected. The model has been used to investigate the relative contribution from each possible explanation.

Our computations allow us to distinguish between these two possible mechanisms. In the simulations described above, two simulation microstructures were constructed from 
micrographs of the AZ31 sheet material. The material representing the microstructure with tensile axis parallel to the extrusion direction had an apparent grain size with $18 \mu \mathrm{m}$, and the texture was such that the basal planes are oriented perpendicular to the loading direction. The microstructure with tensile axis perpendicular to the ED had grain size $9 \mu \mathrm{m}$ and basal planes parallel to the loading direction. Our simulations enable us to create 'virtual' materials with the identical texture, but with the grain size reversed (i.e. with $9 \mu \mathrm{m}$ parallel to the $\mathrm{ED}$ and $18 \mu \mathrm{m}$ perpendicular to the $\mathrm{ED}$, representing grains elongated transverse to the ED). The resulting strain rate vs. stress curves for these additional simulations along with the original results from the simulations with the experimentally correct microstructure characteristics are plotted in Figure 9. The flow stress clearly correlates with grain size, not texture. Similarly, Figure 10 compares the contribution to the total strain rate from each deformation mechanism for the actual materials and the two 'virtual materials'. Again the strain rates correlate with grain size rather than texture. However, a noticeable separation between the plots of corresponding grain size can be observed in Figure 10. For each grain size when the orientation is $0^{\circ}$ to the $\mathrm{ED}$, the contribution from DC is slightly greater, and when the orientation is $90^{\circ}$ to the ED the contribution from GBS is greater. This suggests that GBS is more likely for loading oriented $90^{\circ}$ to the ED, which may be due to the more even distribution of slip on the various systems for this orientation, which would promote a more even distribution of stress, allowing for greater sliding. Thus, the orientation does have an effect on the response of the microstructure to deformation; however, the root of the anisotropy is a result of the difference in the effective grain size rather than orientation.

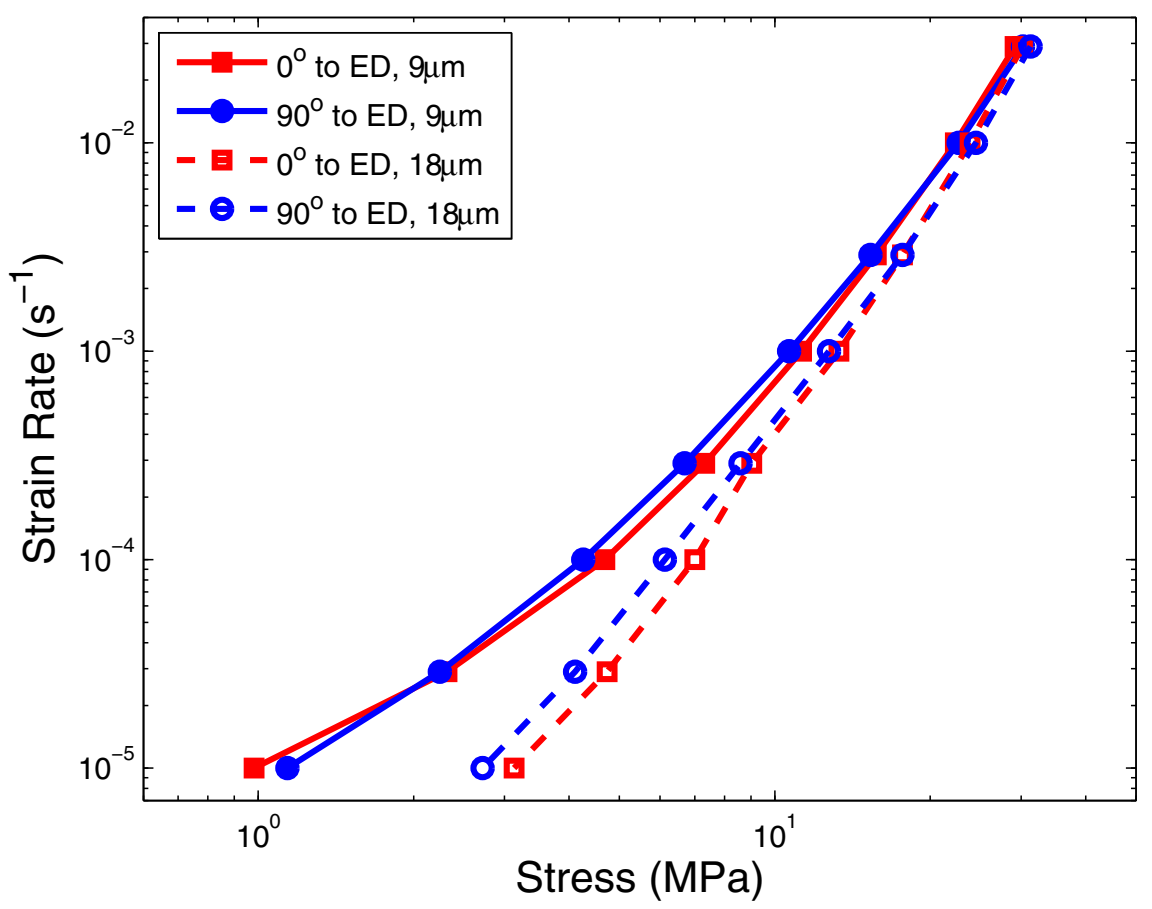

Figure 9 The predicted flow behavior of model microstructures with equiaxed grains, but with experimentally measured textures. Results are shown for model materials with two grain sizes of $9 \mu \mathrm{m}$ and $18 \mu \mathrm{m}$, loaded parallel to the ED and perpendicular to the ED at $450^{\circ} \mathrm{C}$. Note that, for a fixed grain size, only a small anisotropy is observed. 

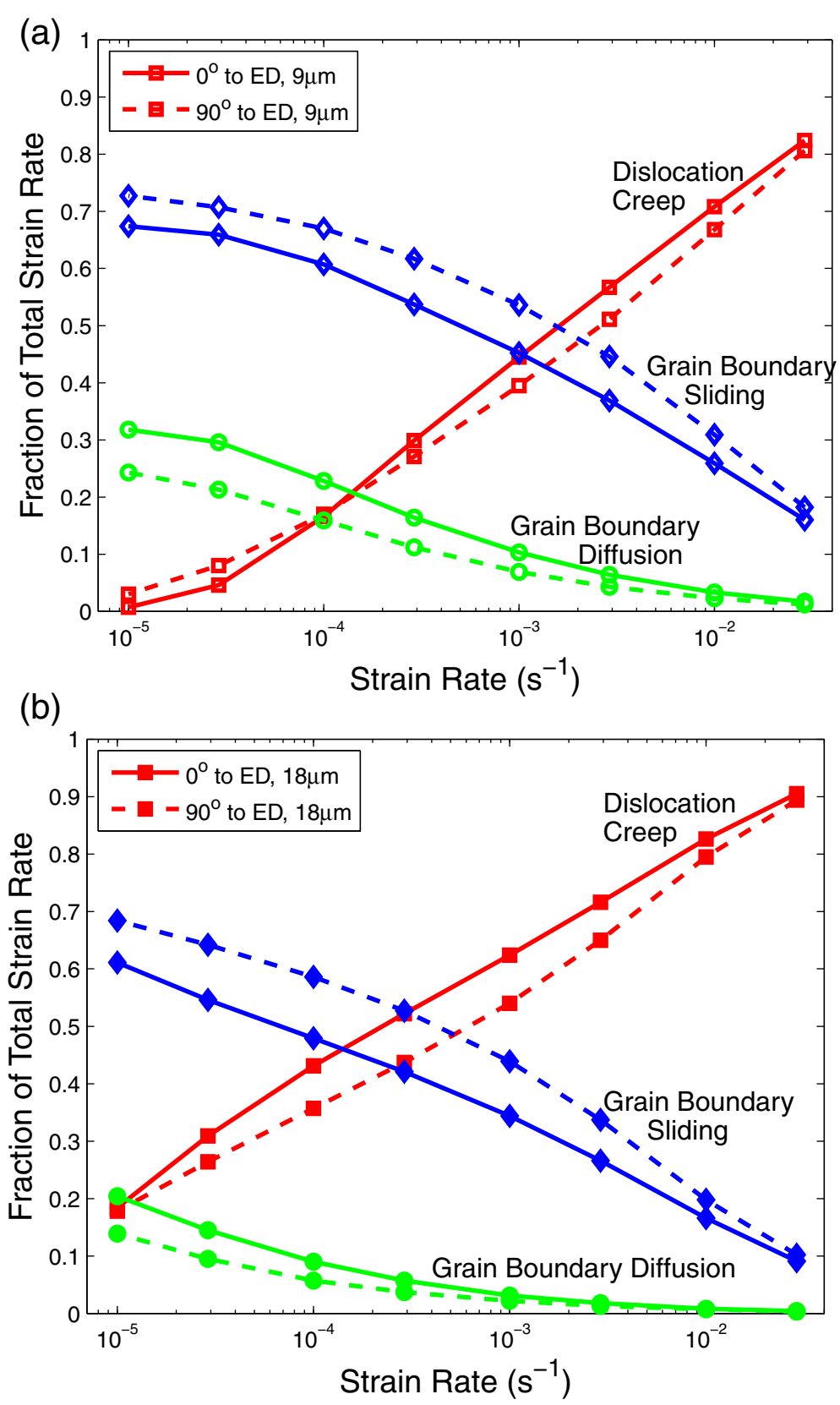

Figure 10 The predicted percent contribution to total strain rate from each deformation mechanism, $\mathrm{DC}, \mathrm{GBD}$, and GBS as a function of strain rate and orientation of the tensile axis at $450^{\circ} \mathrm{C}$ with constant grain size of (a) $9 \mu \mathrm{m}$ and (b) $18 \mu \mathrm{m}$. The difference in deformation mechanisms at a fixed grain size is caused by texture.

\section{Conclusions}

A combination of experiment and numerical simulation was used to determine the flow stress and deformation mechanisms in extruded magnesium alloy AZ31 sheet at temperatures between $350^{\circ} \mathrm{C}$ and $450^{\circ} \mathrm{C}$, and strain rates ranging from $10^{-5}$ to $10^{-2} \mathrm{~s}^{-1}$. Our results show that

1. The flow stress in extruded magnesium alloy sheet is anisotropic, with a higher flow stress for tensile deformation parallel to the extrusion direction than transverse to 
the ED. Material loaded with the tensile axis perpendicular to the ED also has a higher tensile ductility than material loaded parallel to the ED.

2. For both loading orientations, the flow stress has a power-law relationship to strain rate $\dot{\varepsilon}=A \sigma^{n}$. The stress exponent $n$ decreases with strain rate, consistent with a transition in deformation mechanism from grain boundary sliding at low strain rates to dislocation creep at high strain rates. The transition from one mechanism to the other varies with temperature and the orientation of the loading axis.

3. At $450^{\circ} \mathrm{C}$, the critical strain rate where the dominant deformation mechanism transitions from DC to GBS shifts from $1.5 \times 10^{-4} \mathrm{~s}^{-1}$ when the tensile axis is $0^{\circ}$ to the ED to $2.0 \times 10^{-3} \mathrm{~s}^{-1}$ when the tensile axis is $90^{\circ}$ to the ED.

4. At $350^{\circ} \mathrm{C}$, the critical strain rate where the dominant deformation mechanism transitions from DC to GBS shifts from $1.5 \times 10^{-5} s^{-1}$ when the tensile axis is $0^{\circ}$ to the ED to $2.3 \times 10^{-4} \mathrm{~s}^{-1}$ when the tensile axis is $90^{\circ}$ to the ED.

5. For deformation with the tensile axis $0^{\circ}$ to the ED, slip on the prismatic system is dominant followed by slip on the basal and pyramidal system respectively.

6. For deformation with the tensile axis $90^{\circ}$ to the ED, slip on the basal system is dominant followed by slip on the pyramidal and prismatic system respectively.

7. The contribution of each slip system to the total strain rate due to DC is not dependent on strain rate or temperature over the ranges considered.

8. Two microstructural features contribute to the plastic anisotropy of extruded magnesium alloy sheet. The material has an anisotropic texture, with basal planes lying predominantly perpendicular to the extrusion direction. In addition, the grain structure is anisotropic, with grains elongated parallel to the ED. The numerical simulations indicate that the anisotropy in grain shape leads to an increase in grain boundary sliding for material loaded transverse to the ED, and provides the dominant contribution to the plastic anisotropy at elevated temperature. The texture plays a lesser role.

\section{Availability of supporting data}

The data supporting the results of this article are included within the article in graphical form.

\section{Competing interests}

The authors declare that they have no competing interests.

\section{Authors' contributions}

DC performed both the experimental and computational work, and drafted the manuscript. AB developed the microstructure based finite element model, which was adapted by DC adapted for use with magnesium alloys. PK planned the experiments. $\mathrm{AB}$ and PK helped to manage the project and were instrumental in composing the final manuscript. All authors read, discussed, and approved the final manuscript.

\section{Acknowledgements}

This work was supported by the General Motors Collaborative Research Laboratory in Computational Materials Research at Brown University.

\section{Author details}

${ }^{1}$ School of Engineering, Brown University, Providence, RI 02912, USA. ²General Motors Company, 30001 Mound Rd, Warren, MI 48090, USA. ${ }^{3}$ Present Address: College of Engineering, Bucknell University, Lewisburg, PA 17837, USA. 
2. Ecob N, Ralph B (1983) The effect of grain size on deformation twinning in a textured zinc alloy. J Mater Sci 18:2419-2429. 10.1007/BF00541848

3. Lebensohn R, Tome C (1993) A self-consistent anisotropic approach for the simulation of plastic deformation and texture development of polycrystals: application to zirconium alloys. Acta Metallurgica et Materialia 41:2611-2624. 10.1016/0956-7151(93)90130-K

4. Lee HP, Esling C, Bunge HJ (1988) Development of the rolling texture in titanium. Textures and Microstructures 7:317-337. 10.1155/TSM.7.317

5. Philippe M, Beaujean I, Bouzy E et al (1994) Effect of texture and microstructure on the mechanical properties of Zn alloys. MSF 157-162:1671-1674. 10.4028/www.scientific.net/MSF.157-162.1671

6. Philippe M, Bouzy E, Fundenberger J-J (1998) Textures and anisotropy of titanium alloys. MSF 273-275:511-522. 10.4028/www.scientific.net/MSF.273-275.511

7. Philippe M, Esling C, Hocheid B (1988) Role of twinning in texture development and in plastic deformation of hexagonal materials. Textures and Microstructures 7:265-301. 10.1155/TSM.7.265

8. Philippe M, Serghat M, Vanhoutte P, Esling C (1995) Modelling of texture evolution for materials of hexagonal symmetry - II. application to zirconium and titanium a or near a alloys. Acta Metallurgica et Materialia 43:1619-1630 10.1016/0956-7151(94)00329-G

9. Philippe M, Wagner F, Mellab F et al (1994) Modelling of texture evolution for materials of hexagonal symmetry-I. Application to zinc alloys. Acta Metallurgica et Materialia 42:239-250. 10.1016/0956-7151(94)90066-3

10. Kelley EW, Hosford WF (1968) Transactions of the metallurgical society of AIME., pp 242:654-660

11. Philippe M (1994) Texture formation in hexagonal materials. Mater Sci Forum 157-162:1337-1350

12. Hutchinson B, Barnett MR, Ghaderi A et al (2009) Deformation modes and anisotropy in magnesium alloy AZ31. Int J Mat Res (formerly Z Metallkd) 100:556-563. 10.3139/146.110070

13. Krajewski PE, Ben-Artzy A, Mishra RK (2010) Room temperature tensile anisotropy of extruded magnesium plates. In: Agnew SR, Neelameggham NR, Nyberg EA, Sillekens WH (eds) Magnesium Technology. TMS, Warrendale, PA, pp 467-472

14. Xiong F, Davies CHJ (2003) Anisotropy of tensile properties of extruded magnesium alloy AZ31. Mater Sci Forum 426-432:3605-3610

15. Barnett MR (2003) A taylor model based description of the proof stress of magnesium AZ31 during hot working Metall and Mat Trans A 34:1799-1806. 10.1007/s11661-003-0146-5

16. Reed-Hill RE, Robertson WD (1957) Deformation of magnesium single crystals by nonbasal slip. Transactions of the Metallurgical Society of AIME 220:496-502

17. Reed-Hill RE, Robertson WD (1958) Pyramidal slip in magnesium. Transactions of the Metallurgical Society of AIME 221:256-259

18. Ward Flynn PW, Mote J, Dorn JE (1961) Transactions of the Metallurgical Society of AIME 221:1148-1154

19. Agnew SR, Duygulu Ö (2005) Plastic anisotropy and the role of non-basal slip in magnesium alloy AZ31B. Int J Plast 21:1161-1193. 10.1016/j.jijplas.2004.05.018

20. Barnett MR, Ghaderi A, Sabirov I, Hutchinson B (2009) Role of grain boundary sliding in the anisotropy of magnesium alloys. Scr Mater 61:277-280. 10.1016/.jscriptamat.2009.04.001

21. Stanford N, Sotoudeh K, Bate PS (2011) Deformation mechanisms and plastic anisotropy in magnesium alloy AZ31. Acta Mater 59:4866-4874. 10.1016/.actamat.2011.04.028

22. Foley DC, Al-Maharbi M, Hartwig KT et al (2011) Grain refinement vs. crystallographic texture: Mechanical anisotropy in a magnesium alloy. Scr Mater 64:193-196. 10.1016/j.scriptamat.2010.09.042

23. Krajewski PE, Hector LG Jr, Du N, Bower AF (2010) Microstructure-based multiscale modeling of elevated temperature deformation in aluminum alloys. Acta Mater 58:1074-1086. 10.1016/j.actamat.2009.10.023

24. Schroth JG (2004) General Motors' Quick Plastic Forming Process. In: Taleff EM, Friedman PA, Krajewski PE (eds) Advances in Superplasticity and Superplastic Forming. TMS, Warrendale, PA, pp 9-20

25. Barnes AJ (1994) Superplastic forming of aluminum alloys. Mater Sci Forum 170-172:701-714

26. Cipoletti DE, Bower AF, Krajewski PE (2011) A microstructure-based model of the deformation mechanisms and flow stress during elevated-temperature straining of a magnesium alloy. Scr Mater 64:931-934. 10.1016/j. scriptamat.2010.12.033

27. Bower AF, Wininger $\mathrm{E}$ (2004) A two-dimensional finite element method for simulating the constitutive response and microstructure of polycrystals during high temperature plastic deformation. J Mech Phys Solids 52:1289-1317. 10.1016/j.jmps.2003.11.004

28. Freund L, Suresh S (2003) Thin film materials: stress, defect formation, and surface evolution. Cambridge University Press, Cambridge [England]; New York

29. Frost H, Ashby MF (1982) Deformation-mechanism maps: the plasticity and creep of metals and ceramics, 1st edn. Pergamon Press, Oxford [Oxfordshire]; New York

30. Obara T, Yoshinga H, Morozumi S (1973) \{1122\}-1-123\} Slip system in magnesium. Acta Metall 21:845-853. 10.1016/0001-6160(73)90141-7

31. Yoshinaga H, Horiuchi R (1963) Deformation mechanisms in magnesium single crystals compressed in the direction parallel to hexagonal axis. Japan Institute of Metals 4:1-8

32. Yoo M, Agnew S, Morris J, Ho K (2001) Non-basal slip systems in HCP metals and alloys: source mechanisms. Mater Sci Eng A 319-321:87-92. 10.1016/S0921-5093(01)01027-9

33. Cahn J, Taylor J (2004) A unified approach to motion of grain boundaries, relative tangential translation along grain boundaries, and grain rotation. Acta Mater 52:4887-4898. 10.1016/j.actamat.2004.02.048

doi:10.1186/2193-9772-2-4

Cite this article as: Cipoletti et al: Anisotropy in plastic deformation of extruded magnesium alloy sheet during tensile straining at high temperature. Integrating Materials and Manufacturing Innovation 2013 2:4. 